\title{
SYNTHESIS AND STUDY OF EPOXY RESINS BASED ON DIFFERENT BISPHENOLS FOR IMPROVEMENT OF LOCAL ASPHALT
}

\author{
**E.A. Hassan, * S.A. El-Kholy, *A.M.M. Abd El-Rahman and *I.M. Nassar \\ ** Faculty of Science, Al-Azhar University, Nasr City, Cairo, Egypt. \\ *Egyptian Petroleum Research Institute( EPRI), Nasr City, Cairo, Egypt.
}

\begin{abstract}
Four types of bisphenols and their respective low molecular weight epoxy resins (I, II, III and IV) were prepared and characterized. Each of the obtained epoxy resins was applied as an additive (together with high temperature hardener) to two types of local asphalt ( $\mathrm{L}$ and $\mathrm{H}$ types) having different compositions.

The resulting data of the validity of the obtained mixtures concerning the improved properties of asphalt [penetration, softening point, calculated penetration temperature susceptibility (PTI) and penetration index (PI)] are based upon the effect of the quantity and type of epoxy resin, type of the hardener used and also by comparison with the results obtained in presence of the commercial epoxy resin $(\mathrm{V})$ which has a specified low temperature hardener. The optimum conditions obtained for the formulations which lead to the best properties are taken into consideration in the application of such formulations for the improvement of the asphalt to be used in different purposes.

Data obtained revealed that improved asphalt either $(\mathrm{H})$ or $(\mathrm{L})$ type with epoxy III and hardener (1) gave highest values of softening point and penetration grade as compared with unmodified parent asphalt.

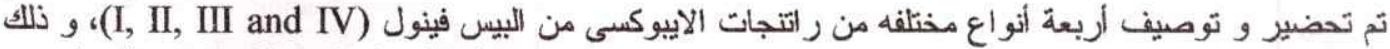

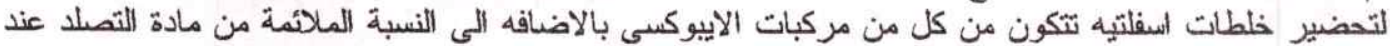

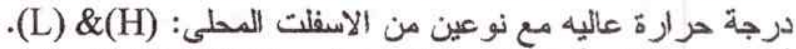

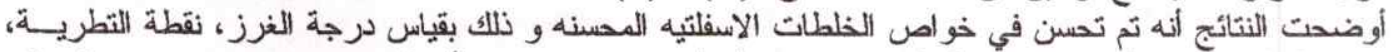

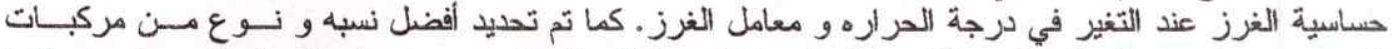

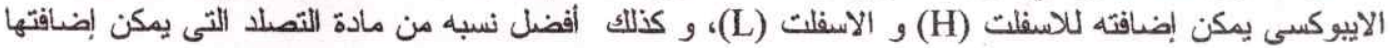

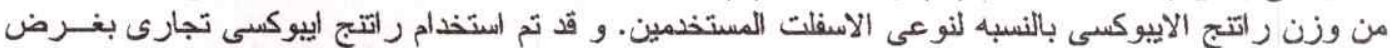

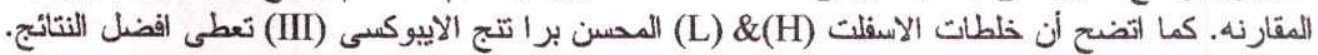

Keywords: Asphalt, Epoxy resins, Penetration temperature susceptibility, penetration index.

\section{INTRODUCTION}

Asphalt pavements are subjected to a wide range of temperatures at which the asphalt should maintain enough stiffness and strength to preveri failures like cracking (at low temperatures) and ruttirg or shoving (at high temperatures). Its properties can be controlled using specifications from tests conducted at different temperatures. Grades, according to the location, should be selected depending on the climate [1].

Polymers have traditionally been utilized to improve the temperature susceptibility of asphalt which is thermoplastic; softens when heated and hardens when cooled. It is hypothesized that improving the binder stiffness at high service temperatures and reducing stiffness at low service temperatures develop an overall improved binder. The resulting binder would possess improved resistance to permanent deformation, thermal cracking, and fatigue cracking [2].

A reported mechanism associated with polymers for improving the properties of asphalt cement is that polymers create a lattice within asphalt by combining small molecules. The larger molecule lattice is more stable under high and low temperatures and thus, resists thermally induced cracking at low service temperatures and permanent deformation or rutting at high service temperature.

Extensive research has been conducted on asphalt additives, aiming for example, at the performance of paving grade cement modified by thermosetting, and thermoplastic resins compared with the performance of unmodified asphalt cement. These resins additives increase the mixture's cohesion, lower the 
temperature susceptibility, improve aggregate retention along with increasing elasticity, and improve the rheological properties of the modified asphalt cement [3-6].

The aim of this work is to determine the optimum compositions of the formulations which result in the best possible penetration, softening point, calculated penetration temperature susceptibility (PTI), penetration index (PI) and thermal susceptibility.

\section{EXPERIMENTAL WORK}

1. Chemicals and Their Properties:

Phenol product of El-Nasr Co. for Coke and Industrial Chemicals, Benzaldehyde of SigmaAldrich Co.Ltd. Grade, Acetophenone of Fluka Chemicals Co., Cyclohexanone of El-Nasr Co. for pharmaceutical chemicals. The hardeners for epoxy resin, viz. phthalic anhydride (1), maleic anhydride (2), trimellitic anhydride (3) and also the other used chemicals were of pure grade. Asphalt 60/70 penetration grade (L) supplied from Refinery Suez Co., Egypt, and asphalt $80 / 100$ penetration grade $(\mathrm{H})$ supplied from El-Nasr Petroleum Co., Alex., c. f. Table (1).

\section{Synthesis of Bisphenols:}

a. Bisphenols prepared from phenol and acetone (A) and also cyclohexanone (D).

To a mixture of phenol (376 gm) and acetone (58 $\mathrm{gm})$, or cyclohexanone $(98 \mathrm{gm})$, at a molar ratio of $4: 1$, in a conical flask conc. $\mathrm{H}_{2} \mathrm{SO}_{4}(50 \mathrm{ml})$ and conc. $\mathrm{HCl}$ gas $(100 \mathrm{ml})$ were added and the mixture shaken for 4 hours. The product was then filtered,washed and finally recrystallized [7].

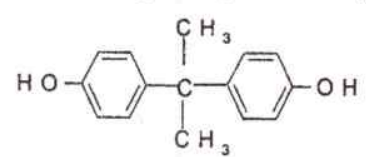

Bisphenol (A)

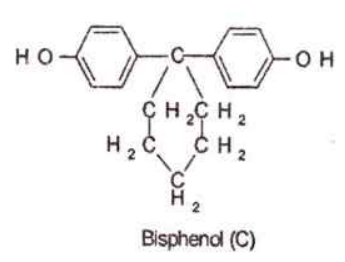

Bisphend (C) b. Bisphenols prepared from phenol and benzaldehyde (B) and also acetophenone (C) [8].

A mixture of phenol $(367 \mathrm{gm})$ and benzaldehyde $(106 \mathrm{gm})$ or acetophenone $(121 \mathrm{gm})$ at molar ratio of $4: 1$ dissolved in toluene in a conical flask was cooled to $-5^{\circ} \mathrm{C}$, and then dry $\mathrm{HCl}$ gas was bubbled over the mixture for 2 hours followed by shaking for one hour. The obtained products were washed till free of phenol, recrystallized and finally dried at $50^{\circ} \mathrm{C}$.

The specifications for all bisphenols (A, B, C, and D) are given in Table (2) and their structures are confirmed with the help of IR, mass spectroscopy, and HNMR analysis. Figures (1-3), illustrate the analysis of the structure of bisphenol A and epoxy resin based on bisphenol $\mathrm{A}$ as an example.

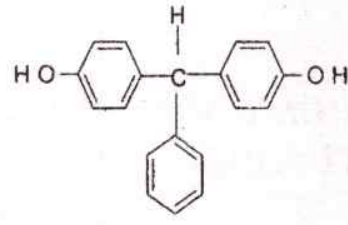

Bisphend (B)

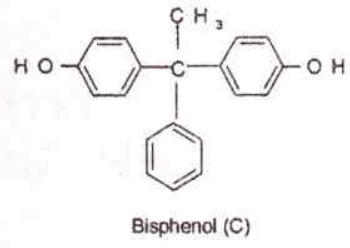

The IR spectra of the bisphenol A given in Figure (1), show a strong sharp band in the region 3420 $3350 \mathrm{~cm}^{-1}$ assigned to phenolic $(\mathrm{OH})$ streching vibrations [9]. The bands at 1580 and $1555 \mathrm{~cm}^{-1}$ correspond to aromatic $\mathrm{C}=\mathrm{C}$ streching vibrations, while the b and at $1275 \mathrm{~cm}^{-1}$ may be assigned to C$\mathrm{OH}$ streching vibrations. The appearance of band at $810 \mathrm{~cm}^{-1}$ for all prepared bisphenols is assigned to C$\mathrm{H}$ and of plane bending for $\mathrm{P}$-substituted aromatic ring. This band confirms the condensation of phenol with the corresponding carbonyl compounds at the Pposition.

Further confirmation for this structure was obtained from mass spectroscopic investigation (c.f. Figure 3). It is important to recognize the parent peaks because they give the molecular weight of the compound, which agrees with the calculated molecular weight of the produced bisphenols Table (2). It is noted that the produced fragments agree with the base peaks determined from the spectra. The $p$ henolic products produced from condensation of phenol with benzaldehyde were indicated from the base peak at $\mathrm{m} / \mathrm{e}=276$, which represents parent peak of the product.

\section{Synthesis of Low Molecular Weight Epoxy Resin [7]:}

Bisphenols (A $232 \mathrm{gm}$ ), (B $281 \mathrm{gm}$ ), (C $295 \mathrm{gm}$ ), and (D $287 \mathrm{gm}$ ) each was separately mixed with epichlorohydrin (235.9 gm) at molar ratio of (1: 3 $\mathrm{w} / \mathrm{w})$ in three-necked flask equipped with stirrer, reflux condenser, and dropping funnel, and placed in water path at $60-70^{\circ} \mathrm{C}$. A solution of $\mathrm{NaOH}(88 \mathrm{gm})$ in $100 \mathrm{ml} \mathrm{H}_{2} \mathrm{O}$ was prepared, $60 \%$ of this solution was added to the above mixture in a period of 2 hours. The second portion $22 \%$ of this solution was added in a period of (15-20 min.), the temperature should not exceed $65-70^{\circ} \mathrm{C}$. The third portion $18 \%$ was added at once, and stirring continued for another $45 \mathrm{~min}$. The obtained resins were separated from the reaction mixture, dissolved in acetone, filtered and then dried at $60-70^{\circ} \mathrm{C}$ till constant weight.

The specifications of the obtained epoxy resins are given in Table (3).

\section{Determination of the specifications of the prepared epoxy resins.}

- Values of epoxy group content, hydroxyl group content and drop falling temperatures (by 
Ubbeblode method) were determined according to the cited methods in the literature $[10,11]$.

- The Dynamic viscosity of the obtained resin was measured using RV 12 Viscometer Haake Co., West Germany.

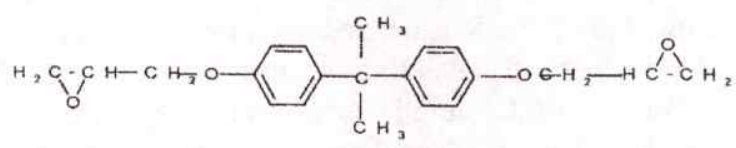
Epoxy Resin(1)
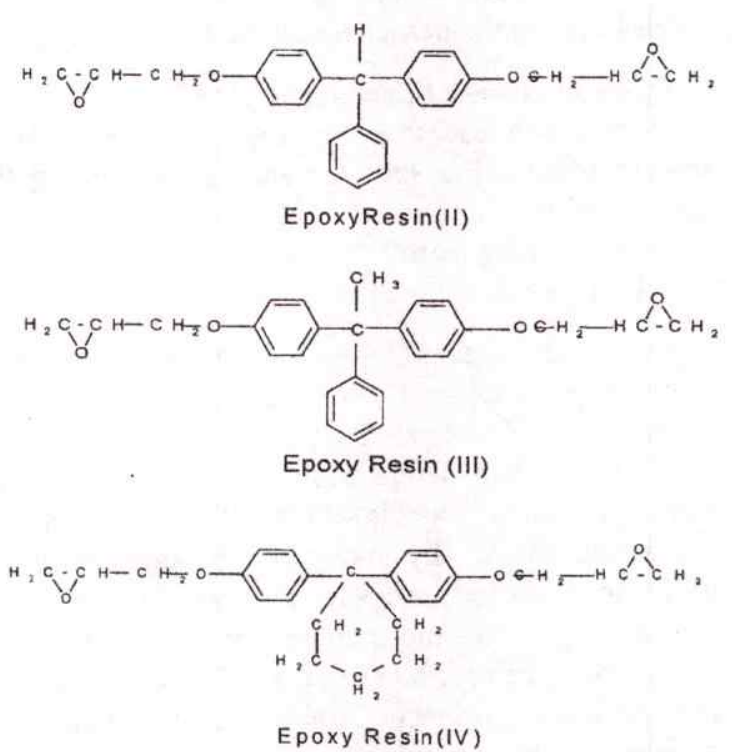

\section{Blending of Asphalt with Epoxy Resin [5].}

The blending technique employed involved heating the asphalt sample to $60-80^{\circ} \mathrm{C}$ followed by thorough mixing with specified amount of epoxy resin and calculated amount of molten hardener in a beaker till homogenous b lend was obtained a nd then p laced in an oven at $150-170^{\circ} \mathrm{C}$. The curing time, resin concentration and hardener concentration, $\%$ of the weight of resin were estimated.

\section{Determination of the physical properties of - asphalt blends.}

Softening Point (Ring\&Ball). The standard test method was carried out a ccording to A STM D 36.

ㅁ Penetration $\left(0.1 \mathrm{~m} / 25^{\circ} \mathrm{C}\right)$. The standard test method was carried out a ccording to A STM D 5 .

\section{RESULTS AND DISCUSSIONS}

The synthesized four types of low molecular weight epoxy resins (I, II, III, and IV) were added separately to each of the studied local asphalt samples (L and H) together with individually calculated amounts of high temperature hardener (1,2, and 3) for asphalt modification. The obtained results of softening point, penetration, calculated PTS and PI were determined and compared with those of unmodified asphalt and of the used commercial epoxy resin (V) and its specified low temperature hardener.

\section{The Factors Affecting the Characteristics of the Obtained}

Asphalt-Epoxy Resin Mixture, are:

\section{i. Mixing temperature.}

Since the used viscous medium, like bitumen can minimize the possibility of interaction between the molecules of the resin and hardeners, i.e. it reduces their chance of collision, the only way to offset such behaviour and produce homogeneity of the mixtures; it was necessary to increase the temperature in order to accelerate the reaction velocity [3]. Consequently, the asphalt, polymer-mixing temperature was around $150-170^{\circ} \mathrm{C}$ which is the asphalt workability temperature.

\section{ii. Curing time.}

In order to find out the suitable time which is necessary for the curing, of the studied asphalt-epoxy mixtures, 24 different types of mixtures were prepared, the compositions of the mixtures of asphalt $60 / 70(\mathrm{~L})$ or $80 / 100(\mathrm{H})$ is $90 \%$ asphalt, plus one of the used types of low molecular weight epoxy resins $(10 \%)$, based on [bisphenol A (I), Bisphenol of benzaldehyde (II), bisphenol of acetophenone (III), and bisphenol of cyclohexanone (IV)]. Each of the used hardeners, [phthalic anhydride (1), maleic anhydried (2), and trimellitic anhydried (3)] was added s eparately at a ratio of $10 \%$ of the weight of the used epoxy resins. Therefore the symbols for compositions of the studied mixtures; ( $\mathrm{H} \mathrm{I} \mathrm{1),} \mathrm{(H} \mathrm{II}$ 1), (H III 1), (H IV 1), (H I 2), (H II 2), (H III 2), (H IV 2), (H I 3), (H II 3), (H III 3), and (H IV 3) specify asphalt $80 / 100$, while for asphalt $60 / 70$ mixtures the respective abbreviations are (L I 1), (L II 1), (L III 1), (L IV 1), (L I 2), (L II 2), (L III 2), (L IV 2), (L I 3), (L II 3), (L III 3), and (L IV 3). The s tudied physical properties of the samples after curing at different time intervals $(5,10,15,20$, and 25 hours) were penetration, $0.01 \mathrm{~mm}$, and softening point, ${ }^{\circ} \mathrm{C}$.

Results given in Table (5) show that the penetration of the mixtures decreases at first with increasing time of curing, and reach their lowest values of penetration at curing time between 10-15 hours. These values increase with further increasing time of curing. On the other hand the values of softening point increase with increasing time of curing till reaching their highest values of softening point for curing time between 10-15 hours for all mixtures after which they decrease. This means that the suitable time for curing for all mixtures ranged between 10-15 hours. 
Values of penetration index (PI) and penetration susceptibility (PTS) which give indications about the hardness, and plastic flow to the prepared formulations, were calculated with help of the obtained values of penetration and softening point for the above mentioned mixtures according to the following equations $[3,4]$ :

PTS $=$ Log $800-\log$ penetration / Softening point
at $25^{\circ} \mathrm{C}$

$$
P I=(30 / 1+90 \text { PTS })-10
$$

Results given in Table (6) show that the lowest values of PTS accompanied by highest values of PI for the same sample are recorded for curing times between 10-15 hours, means that the mixtures with the highest rheologic properties acquire the highest values of PI and lowest values of PTS, such mixtures acquire higher hardness as compared with other mixtures [4].

\section{iii. Curing agent, \%.}

For the selected local asphalt samples AC 60/70 Suez (L), and 80/100 Alex. (H), each was mixed with $10 \% \mathrm{w} / \mathrm{w}$ of the prepared low molecular weight epoxy resin (I, II, III, and IV) to give the previously mentioned mixtures. Each of these mixtures was cured at $150-170^{\circ} \mathrm{C}$ for 15 hours using different percentages by weight of the specified hardener, phthalic anhydride (1), $(10,20,30,40$, and $50 \%$ respectively relative to fixed weight of the epoxy resin). The same procedure was applied on the other two hardeners, maleic anhydride (2), and trimellitic anhydride (3). The physical tests such as penetration, and softening point were estimated for the obtained cured mixtures to investigate the suitable ratio of used hardeners needed to give the highest hardness as predicted from the values of low penetration and high softening point $[3,4]$.

Results given in Table (7) show that the values of penetration decrease with increasing the percentage of hardener up to $40 \%$ which gives the lowest values of penetration and the highest values of hardness for all the studied mixtures of asphalt 80/100 Alex. (H).

The respective values of softening point increase with increasing the ratio of hardener till $40 \%$ after which the respective softening point decreases.

The values of penetration for all mixtures based on asphalt $60 / 70$ Suez (L), give the lowest values of penetration and highest values of softening point in presence of hardener quantity of $30 \%$ of the weight of the epoxy-resin [12].

It is probable that the difference in the values of quantities of added hardeners which are equal to $40 \%$ of the weight of the epoxy resin for a sphalt $80 / 100$ $(\mathrm{H})$, as compared to $30 \%$ of the weight of the epoxy resin for asphalt $60 / 70(\mathrm{~L})$, could be attributed to the different constitutions of the studied asphalt which together with the added epoxy resin could be reflected on the studied property.

Moreover further higher values of hardeners than the optimum values for each of the studied asphalt formulations which are accompanied by increase in the values of penetration and decrease of the softening point, could be accompanied by an increase in the acidity of the mixtures obtained from excess acidic hardeners at the such workability temperature which could lead to the destruction of the formed bonds between the hardener and the resin [13].

\section{iv. Optimum ratio of added epoxy resin.}

It was also essential to investigate the suitable amount of epoxy resin necessary for obtaining the best possible improvement (lowest penetration and highest s oftening p oint) for the selected two asphalt samples (L\&H).

Each of the prepared epoxy resins were added in different percentages to the asphalt sample $(10,20$, 30,40 , and $50 \%$ respectively), each was mixed with $40 \%$ of used high temperature curing agent (1), (2), and (3) in case of asphalt $80 / 100(\mathrm{H})$ and $30 \%$ in case of asphalt $60 / 70$ (L) and cured at the previously determined curing temperature for the respective curing time. Also, the commercial epoxy resin was added to a sphalt $w$ ith the s ame different $r$ atios with its specified hardener. After that, the values of penetration, and softening point were measured.

The obtained data listed in Table (8) show that all tested mixtures based on asphalt $80 / 100(\mathrm{H})$ gave the lowest values of penetration and highest values of softening point at quantities of epoxy between 30 $40 \%$ of the weight of the asphalt [13].

According to the type of hardener the lowest values of penetration and consequently the highest values of softening point proceed in the following order $1>3$ $>2$.

According to the type of epoxy resin, the values of the above mentioned properties proceed in the following order of the prepared formulations, $\mathrm{H}$ III 1 $>\mathrm{H} \mathrm{II} 1>\mathrm{H} \mathrm{I} 1>\mathrm{H}$ IV $1>\mathrm{H} \mathrm{V}$. It is probable that such values proceed according to the possibility of the rotation of the central carbon atom of the prepared bisphenol in resulting epoxy resin with temperature. This means that the easier rotation around the central carbon atom leads to the higher penetration and lower softening point, the difficult rotation leads to lower penetration and higher softening point values.

For mixtures based on asphalt $60 / 70$ (L), data given in Table (8) revealed that, all mixtures gave the lowest values of penetration and highest values of softening point at epoxy resin content of $20 \%$ of the 
weight of asphalt. This percent is correlated with the experimentally added quantities of epoxy resins in the cited literature.

According to the type of epoxy resin, the obtained lowest penetration and highest softening point proceed according to the following order of the prepared formulations, L III $1>$ L II $1>$ L I $1>$ L IV $1>$ L V.

\section{References}

[1] Hussein, Bahaia, University of WisconsimMadison, Department of Engineering Professional Development, Wisconsim, Transportation Bulletin, March 1996.

[2] Brown, S.F., F ice, F iht, F iat, A ciarb, University of Nottingham, UK, R.D. Rowlett and J. L. Boucher, Center for Construction Materials Technology, USA, Report, 1990.

[3] Abd El-Rahman, A.M.M., M. Sc. Thesis, "Preparation and Study of Mixtures Using Asphalt", Presented to Faculty of Science, AlAzhar University, 1989.

[4] Abd El-Rahman, A.M.M., Ph. D. Thesis, "A Study of Some Polymeric-Bituminous Coatings and Their Synthesis", Presented to Faculty of Science, Al-Azhar University, 1999.

[5] Nassar I.M., M. Sc. Thesis, "Improvement of Local Asphalt Characteristics by Using Some Polymers for Wider Fields of Applications",
Presented to Faculty of Science, Al-Azhar University, 2003.

[6] Abd El-Rahman, A.M.M., Swelam, A.A., Six International Scientific Conference (Science, Development, and Environment) by Faculty of Science Al-Azhar University, Cairo, 25-27 March, 2003.

[7] Motawie, A.M.H., Ph. D. Thesis, Presented to Faculty of Science, Al-Azhar University, 1983.

[8] Islam, A.M., Hassan, E.A., Rashad, M.E. and Rashad, M.M., Egypt. J. Chem. 20 N0 5, P 483490, 1977.

[9] Pavia D.L., Lampman G.M. and Kriz G.S., Introduction to spectroscopy, W.B. Saunders Co., P 47, 1979.

[10] May, C.A., Tanaka, Y.; Epoxy Resins, Chemistry and Technology, Marcel Dekkar, TNC, New York, 1973.

[11] Konovalalov, P.G., Shnederova, V.V.; Laboratory Practice in the Chemistry of Membrane Forming and Technology of Paint and Pigments, Rastov Pub. 1963.

[12] Denning, JH, and Jcarsweil, "Improvements in rolled-asphalt surfacing by the addition of sulphur", Environment Department of Transport, TRRL Report LR 963, Crowthorne, 1981.

[13] Misra, G.S., Former Professor and Head Department of Chemistry, University of Jabalpur and Jammu and Ex-Director, Indian Lac Research Institute Namkum, Ranchi, Wiley Eastern Limited 


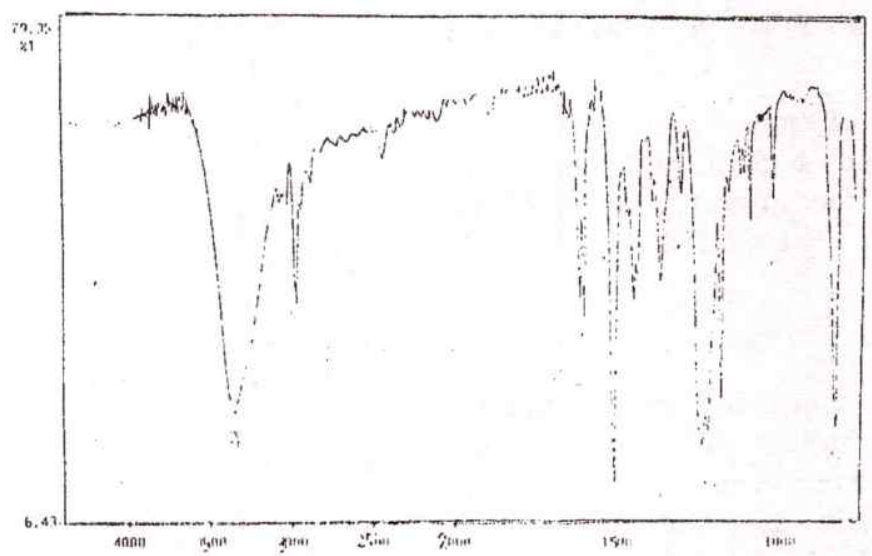

Figure 1. IR Spectrum of Bisphenol Batsed on Acelone.

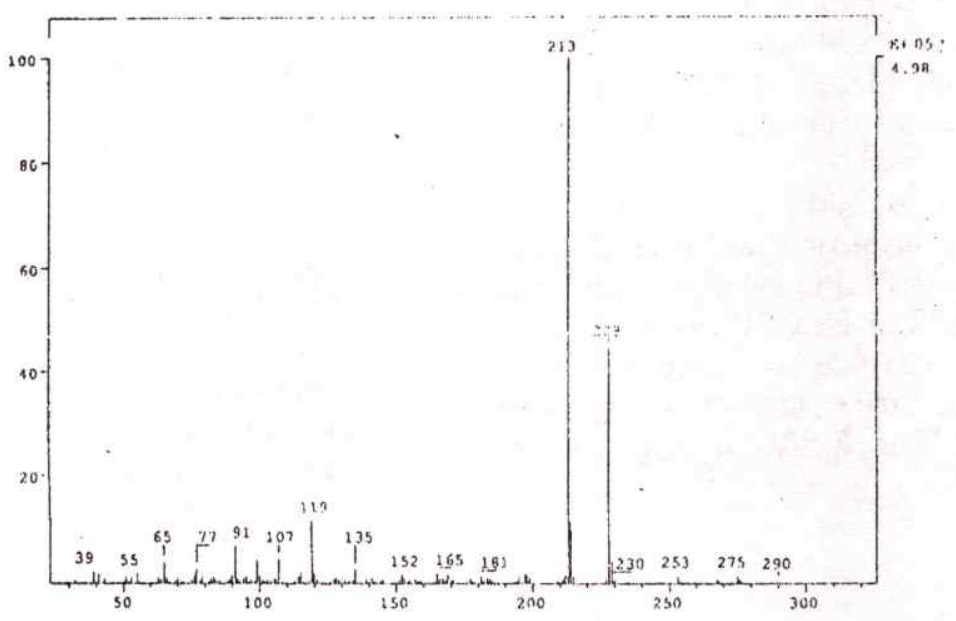

Figure 2. Mass Spectrum of Bisphenol Based on Acetone.

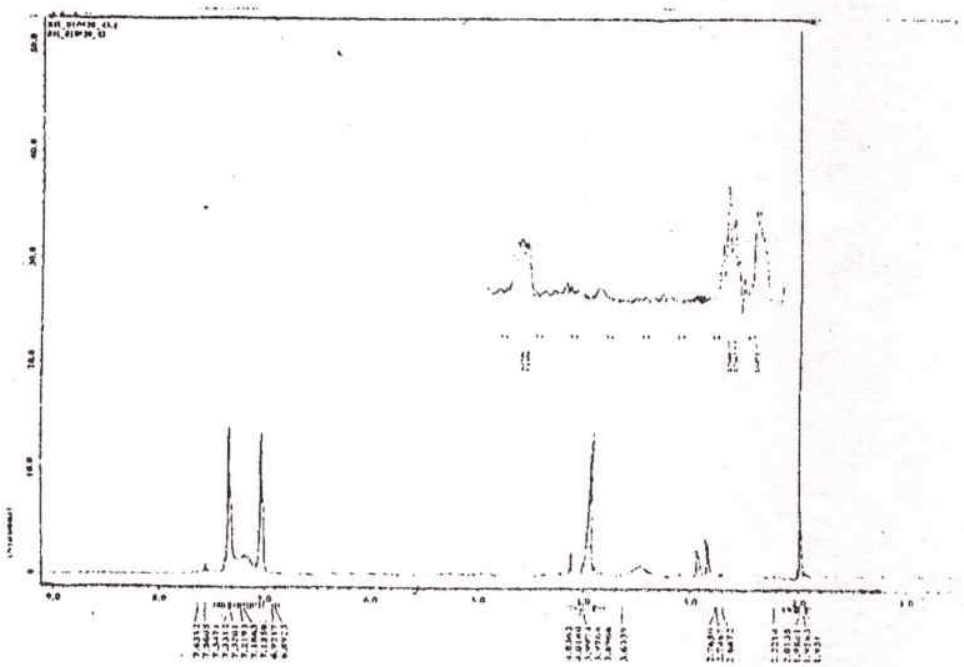

Figure 3. IINMR Spectrum of lipoxy Resin Batsed on Bisplenol $A$. 


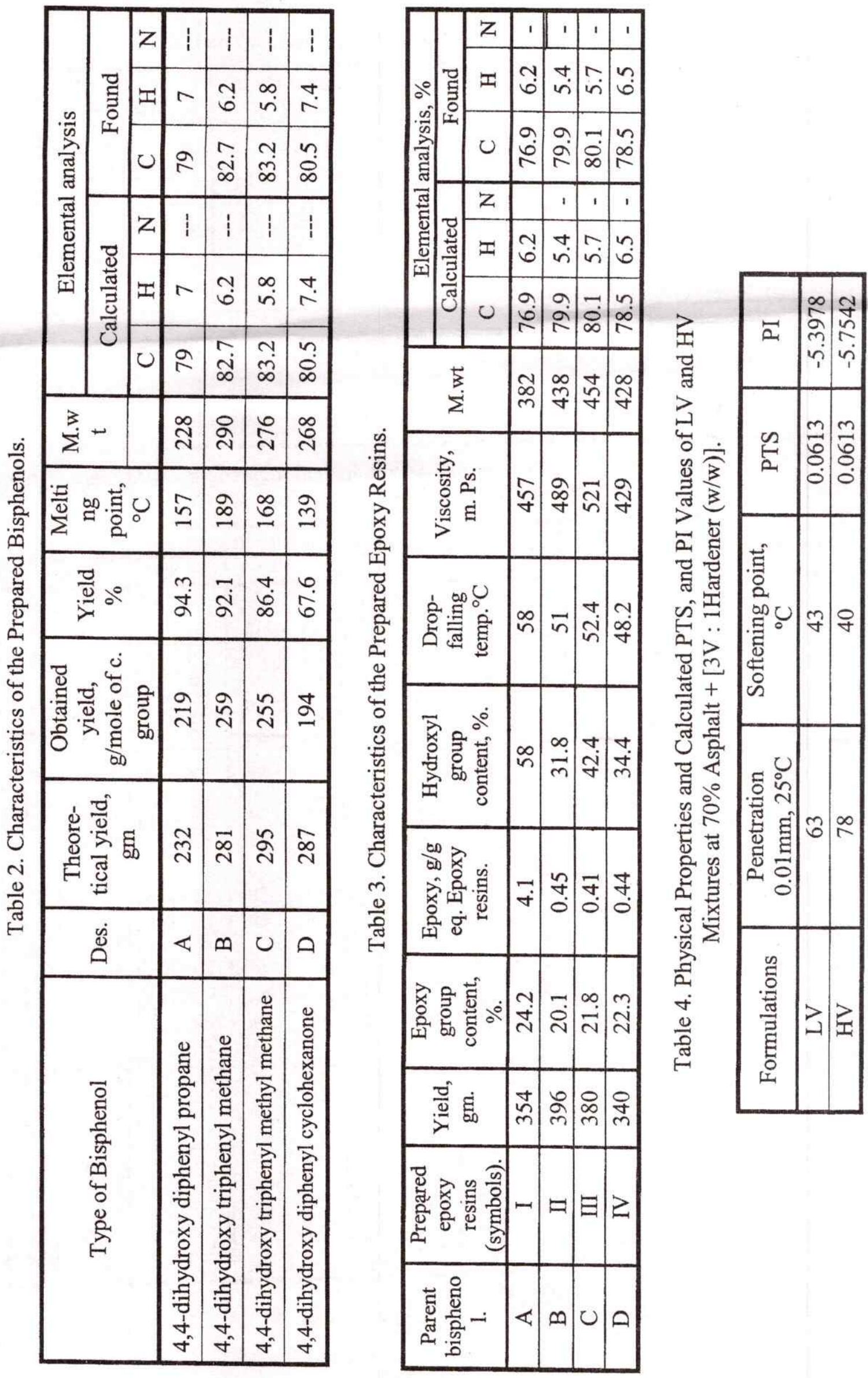


Table1. Physical and Chemical Characteristics of the Selected Two Asphalts ( $\mathrm{L}$ and $\mathrm{H})$.

\begin{tabular}{|l|c|c|}
\hline \multicolumn{1}{|c|}{ Physical Properties(ASTM D-946) } & $\begin{array}{c}\text { Asphalt 60/70 } \\
\text { Suez }(\mathbf{L})\end{array}$ & $\begin{array}{c}\text { Asphalt 80/100 } \\
\text { Alex. (H) }\end{array}$ \\
\hline Solubility in trichloroethylene, $\%$ & 99.0 & 99.0 \\
\hline Flash Point, ${ }^{\circ} \mathrm{F}($ Cleveland open cup) & 450 & 250 \\
\hline Kinematic viscosity at $135^{\circ} \mathrm{C}$, C.st. & 357 & 257 \\
\hline Absolute viscosity at $60^{\circ} \mathrm{C}$, poise & 2560 & 973 \\
\hline Softening Point, Ring and Ball, ${ }^{\circ} \mathrm{C}$ & 47 & 41 \\
\hline Penetration at $77^{\circ} \mathrm{F}\left(25^{\circ} \mathrm{C}\right) 100 \mathrm{~g}, 5 \mathrm{~S}$ & 65 & 94 \\
\hline Ductility at $77^{\circ} \mathrm{F}\left(25^{\circ} \mathrm{C}\right), 5 \mathrm{~cm} / \mathrm{min} ., \mathrm{cm}$ & +150 & $>150$ \\
\hline Chemical Constituents, $W t^{\circ} /$ & \multicolumn{2}{|c|}{} \\
\hline Oil & 25.5 & 35.62 \\
\hline Wax Content of oil portion & 4.4 & 9.32 \\
\hline Asphaltene & 20.8 & 18.26 \\
\hline Resins & 53.6 & 36.8 \\
\hline
\end{tabular}

Table 5. Effect of Curing Time on the Values of Penetration and Softening Point for Formulations Consisting of $90 \%$ Asphalt $+10 \%$ [resin $+10 \%$ hardener] Cured at $150-170^{\circ} \mathrm{C}$.

\begin{tabular}{|c|c|c|c|c|c|c|c|c|c|c|c|}
\hline \multirow{3}{*}{ Formulations } & \multirow{3}{*}{ Specifications } & \multicolumn{10}{|c|}{ Curing time, (hrs) } \\
\hline & & \multicolumn{2}{|c|}{5} & \multicolumn{2}{|c|}{10} & \multicolumn{2}{|c|}{15} & \multicolumn{2}{|c|}{20} & \multicolumn{2}{|c|}{25} \\
\hline & & $\mathrm{H}$ & $\mathrm{L}$ & $\mathrm{H}$ & $\mathrm{L}$ & $\mathrm{H}$ & $\mathrm{L}$ & $\mathrm{H}$ & L & $\mathrm{H}$ & L \\
\hline \multirow{2}{*}{ H/L I 1} & Penetration & 72 & 45 & 61 & 42 & 50 & 46 & 53 & 46 & 54 & 50 \\
\hline & Sof. point & 48 & 53 & 52 & 59 & 51 & 57 & 46 & 53 & 52 & 50 \\
\hline \multirow{2}{*}{ H/L II 1} & Penetration & 63 & 43 & 49 & 40 & 48 & 40 & 54 & 44 & 52 & 45 \\
\hline & Sof. point & 51 & 56 & 50 & 56 & 58 & 60 & 51 & 55 & 53 & 52 \\
\hline \multirow[b]{2}{*}{ H/L III 1} & Penetration & 42 & 40 & 62 & 34 & 61 & 36 & 59 & 37 & 56 & 41 \\
\hline & Sof. point & $\begin{array}{c}54 . \\
5\end{array}$ & 55 & 52 & 61 & 52 & 56 & 52 & 53 & 50 & 51 \\
\hline \multirow{2}{*}{ H/L IV 1} & Penetration & 67 & 44 & 59 & 41 & 52 & 43 & 53 & 45 & 56 & 45 \\
\hline & Sof. point & 47 & 59 & 54 & 61 & 52 & 58 & 52 & 54 & 50 & 51 \\
\hline \multirow{2}{*}{$\mathrm{H} / \mathrm{L}$ I 2} & Penetration & 65 & 47 & 59 & 44 & 62 & 40 & 64 & 43 & 67 & 48 \\
\hline & Sof. point & 52 & 55 & 58 & 58 & 55 & 58 & 51 & 54 & 49 & 51 \\
\hline \multirow{2}{*}{$\mathrm{H} / \mathrm{L}$ II 2} & Penetration & 60 & 44 & 56 & 41 & 59 & 40 & 62 & 42 & 65 & 45 \\
\hline & Sof. point & 51 & 52 & 57 & 54 & 53 & 54 & 50 & 51 & 48 & 47 \\
\hline \multirow{2}{*}{ H/L III 2} & Penetration & 63 & 42 & 57 & 40 & 57 & 39 & 60 & 39 & 64 & 41 \\
\hline & Sof. point & 51 & 51 & 55 & 53 & 56 & 56 & 50 & 52 & 48 & 49 \\
\hline \multirow{2}{*}{ H/L IV 2} & Penetration & 66 & 48 & 61 & 45 & 61 & 41 & 64 & 43 & 68 & 47 \\
\hline & Sof. point & 54 & 50 & 60 & 52 & 60 & 53 & 57 & 51 & 53 & 50 \\
\hline \multirow{2}{*}{ H/L I 3} & Penetration & 62 & 51 & 59 & 48 & 57 & 48 & 57 & 52 & 60 & 55 \\
\hline & Sof. point & 56 & 57 & 56 & 60 & 59 & 58 & 57 & 55 & 53 & 53 \\
\hline \multirow{2}{*}{ H/L II 3} & Penetration & 59 & 48 & 56 & 45 & 52 & 47 & 52 & 50 & 57 & 52 \\
\hline & Sof. point & 61 & 60 & 61 & 62 & 64 & 59 & 63 & 56 & 59 & 55 \\
\hline \multirow{2}{*}{ H/L III 3} & Penetration & 60 & 50 & 57 & 47 & 53 & 49 & 56 & 51 & 59 & 54 \\
\hline & Sof. point & 58 & 59 & 59 & 61 & 61 & 61 & 57 & 58 & 52 & 56 \\
\hline \multirow{2}{*}{$\mathrm{H} / \mathrm{L}$ IV 3} & Penetration & 63 & 52 & 61 & 49 & 59 & 49 & 62 & 51 & 64 & 56 \\
\hline & Sof. point & 56 & 56 & 58 & 59 & 63 & 58 & 59 & 55 & 55 & 52 \\
\hline
\end{tabular}

Where: $\mathrm{H}$ is asphalt $80 / 100$, and $\mathrm{L}$ is asphalt $60 / 70$

(I, II, III, and IV) are the four different prepared epoxy resins.

$(1,2$, and 3$)$ are the used hardeners. 
Table 6. Effect of Curing Time on the Values of (PTS) and (PI) for Formulations Consisting of 90 $\%$ Asphalt $+10 \%$ [resin $+10 \%$ hardener] Cured at $150-170^{\circ} \mathrm{C}$.

\begin{tabular}{|c|c|c|c|c|c|c|c|c|c|c|c|}
\hline \multirow{3}{*}{$\begin{array}{c}\text { Formulatio } \\
\mathrm{ns}\end{array}$} & \multirow{3}{*}{$\begin{array}{c}\text { Specific } \\
\text { ations }\end{array}$} & \multicolumn{10}{|c|}{ Curing time, (hrs) } \\
\hline & & \multicolumn{2}{|c|}{5} & \multicolumn{2}{|c|}{10} & \multicolumn{2}{|c|}{15} & \multicolumn{2}{|c|}{20} & \multicolumn{2}{|c|}{25} \\
\hline & & $\mathrm{H}$ & L & $\mathrm{H}$ & L & $\mathrm{H}$ & L & $\mathrm{H}$ & L & $\mathrm{H}$ & L \\
\hline \multirow{2}{*}{$\mathrm{H} / \mathrm{L}$ I 1} & PTS & 0.0217 & 0.0235 & 0.0214 & 0.0216 & 0.0236 & 0.0217 & 0.0256 & 0.0234 & 0.0225 & 0.0240 \\
\hline & PI & 0.159 & 0.369 & 0.252 & 0.190 & 0.396 & 0.159 & 0.920 & 0.341 & 0.082 & 0.506 \\
\hline \multirow{2}{*}{$\mathrm{H} / \mathrm{L}$ II 1} & PTS & 0.0216 & 0.0236 & 0.0242 & 0.0232 & 0.0219 & 0.0216 & 0.0229 & 0.0229 & 0.0223 & 0.0240 \\
\hline & PI & 0.190 & 0.396 & 0.560 & 0.284 & 0.380 & 0.190 & 0.199 & 0.199 & 0.0232 & 0.506 \\
\hline \multirow{2}{*}{ H/L III 1} & PTS & 0.0234 & 0.0236 & 0.0213 & 0.0224 & 0.0214 & 0.0240 & 0.0217 & 0.0251 & 0.0230 & 0.0253 \\
\hline & PI & 0.341 & 0.396 & 0.280 & 0.053 & 0.250 & 0.506 & 0.082 & 0.794 & 0.228 & 0.845 \\
\hline \multirow{2}{*}{ H/L IV 1} & PTS & 0.0229 & 0.213 & 0.0209 & 0.0211 & 0.0219 & 0.0218 & 0.0226 & 0.0231 & 0.0230 & 0.0245 \\
\hline & PI & 0.0232 & 0.284 & 0.506 & 0.348 & 0.198 & 0.128 & 0.224 & 0.256 & 0.231 & 0.639 \\
\hline \multirow{2}{*}{$\mathrm{H} / \mathrm{L}$ I 2} & PTS & 0.020 & 0.0223 & 0.019 & 0.0217 & 0.020 & 0.0224 & 0.021 & 0.0235 & 0.021 & 0.0239 \\
\hline & PI & 0.714 & -0.023 & 1.070 & 0.159 & 0.714 & -0.05 & 0.0380 & -0.369 & 0.380 & -0.479 \\
\hline \multirow{2}{*}{$\mathrm{H} / \mathrm{L}$ II 2} & PTS & 0.022 & 0.024 & 0.020 & 0.0238 & 0.021 & 0.024 & 0.022 & 0.025 & 0.022 & 0.0265 \\
\hline & PI & 0.067 & -0.50 & 0.714 & -0.45 & 0.380 & -0.50 & 0.067 & -0.769 & 0.067 & $-1,13$ \\
\hline \multirow{2}{*}{ H/L III 2} & PTS & 0.021 & 0.025 & 0.020 & 0.0248 & 0.020 & 0.023 & 0.022 & 0.0252 & 0.022 & 0.026 \\
\hline & PI & 0.380 & -0.769 & 0.714 & -0.717 & 0.714 & -0.228 & 0.067 & -0.82 & 0.067 & -1.01 \\
\hline \multirow{2}{*}{ H/L IV 2} & PTS & 0.020 & 0.0244 & 0.0188 & 0.024 & 0.0185 & 0.0243 & 0.0199 & 0.0248 & 0.020 & 0.0246 \\
\hline & PI & 0.714 & -0.61 & 1.140 & -0.50 & 1.257 & -0.58 & 0.748 & -0.717 & 0.714 & -0.66 \\
\hline \multirow{2}{*}{$\mathrm{H} / \mathrm{L}$ I 3} & PTS & 0.0198 & 0.0206 & 0.020 & 0.0203 & 0.0194 & 0.021 & 0.020 & 0.0215 & 0.021 & 0.0214 \\
\hline & PI & 0.783 & 0.511 & 0.714 & 0.611 & 0.924 & 0.38 & 0.714 & 0.221 & 0.380 & 0.252 \\
\hline \multirow{2}{*}{$\mathrm{H} / \mathrm{L}$ II 3} & PTS & 0.0185 & 0.0203 & 0.0189 & 0,0201 & 0.0185 & 0.0208 & 0.0188 & 0.0215 & 0.0194 & 0.0215 \\
\hline & PI & 1.257 & 0.611 & 1.106 & 0.679 & 1.257 & 0.445 & 1.140 & 0.221 & 0.924 & 0.221 \\
\hline \multirow{2}{*}{ H/L III 3} & PTS & 0.0193 & 0.0201 & 0.0194 & 0.0209 & 0.0193 & 0.019 & 0.020 & 0.0208 & 0.021 & 0.0202 \\
\hline & PI & 0.960 & 0.679 & 0.924 & 0.413 & 0.960 & 1.07 & 0.714 & 0.445 & 0.380 & 0.645 \\
\hline \multirow{2}{*}{$\mathrm{H} / \mathrm{L}$ IV 3} & PTS & 0.0197 & 0.0211 & 0.0192 & 0.0205 & 0.0179 & 0.0209 & 0.0188 & 0.0217 & 0.0199 & 0.0222 \\
\hline & PI & 0.810 & 0.348 & 0.997 & 0.544 & 1.48 & 0.413 & 1.140 & 0,159 & 0.748 & 0.006 \\
\hline
\end{tabular}

Where: $\mathrm{H}$ is asphalt $80 / 100$, and $\mathrm{L}$ is asphalt $60 / 70$.

(I, II, III, and IV) are the four different prepared epoxy resins.

$(1,2$, and 3$)$ are the used hardeners. 
Table 7. Effect of Curing agent of the wt. of Epoxy Resin on the Values of Penetration and Softening Point for Formulations Consisting of $90 \%$ Asphalt $+10 \%$ [resin $+10-50 \%$ hardener] Cured at 150 $170^{\circ} \mathrm{C}$ for $15 \mathrm{hrs}$.

\begin{tabular}{|c|c|c|c|c|c|c|c|c|c|c|c|}
\hline \multirow{3}{*}{ Formulations } & \multirow{3}{*}{ Specifications } & \multicolumn{10}{|c|}{ Curing agent, wt $\%$} \\
\hline & & \multicolumn{2}{|c|}{10} & \multicolumn{2}{|c|}{20} & \multicolumn{2}{|c|}{30} & \multicolumn{2}{|c|}{40} & \multicolumn{2}{|c|}{50} \\
\hline & & H & $\mathbf{L}$ & $\mathbf{H}$ & $\mathbf{L}$ & H & $\mathrm{L}$ & H & L & $\mathbf{H}$ & $\mathrm{L}$ \\
\hline \multirow{2}{*}{ H/L I 1} & Penetration & 50 & 42 & 48 & 38 & 46 & 35 & 46 & 39 & 49 & 44 \\
\hline & Sof. point & 51 & 57 & 53 & 61 & 55 & 61 & 59 & 57 & 53 & 53 \\
\hline \multirow{2}{*}{ H/L II 1} & Penetration & 48 & 40 & 45 & 36 & 42 & 33 & 42 & 37 & 46 & 41 \\
\hline & Sof. point & 58 & 58 & 58 & 62 & 59 & 64 & 61 & 58 & 56 & 54 \\
\hline \multirow{2}{*}{ H/L III 1} & Penetration & 42 & 34 & 40 & 32 & 37 & 30 & 34 & 33 & 43 & 36 \\
\hline & Sof. point & 54 & 59 & 57 & 62 & 58 & 65 & 60 & 60 & 55 & 56 \\
\hline \multirow{2}{*}{ H/L IV 1} & Penetration & 59 & 41 & 55 & 38 & 53 & 34 & 49 & 38 & 54 & 43 \\
\hline & Sof. point & 52 & 58 & 54 & 60 & 61 & 63 & 61 & 60 & 56 & 52 \\
\hline \multirow{2}{*}{$\mathrm{H} / \mathrm{L}$ I 2} & Penetration & 59 & 57 & 56 & 54 & 54 & 54 & 51 & 56 & 55 & 58 \\
\hline & Sof. point & 58 & 59 & 58 & 59 & 59 & 61 & 59 & 58 & 56 & 56 \\
\hline \multirow{2}{*}{$\mathrm{H} / \mathrm{L}$ II 2} & Penetration & 56 & 52 & 53 & 49 & 51 & 47 & 49 & 50 & 54 & 53 \\
\hline & Sof. point & 57 & 64. & 59 & 65 & 61 & 65 & 61 & 62 & 58 & 60 \\
\hline \multirow{2}{*}{ H/L III 2} & Penetration & 57 & 53 & 55 & 51 & 52 & 49 & 52 & 52 & 54 & 55 \\
\hline & Sof. point & 55 & 61 & 58 & 62 & 60 & 64 & 57 & 61 & 54 & 59 \\
\hline \multirow{2}{*}{$\mathrm{H} / \mathrm{L}$ IV 2} & Penetration & 61 & 59 & 58 & 56 & 54 & 52 & 54 & 54 & 57 & 57 \\
\hline & Sof. point & 60 & 63 & 61 & 64 & 63 & 66 & 64 & 63 & 59 & 61 \\
\hline \multirow{2}{*}{$\mathrm{H} / \mathrm{L}$ I 3} & Penetration & 57 & 48 & 53 & 46 & 51 & 44 & 51 & 44 & 55 & 47 \\
\hline & Sof. point & 59 & 60 & 59 & 61 & 62 & 63 & 64 & 62 & 58 & 59 \\
\hline \multirow{2}{*}{ H/L II 3} & Penetration & 52 & 45 & 50 & 41 & 45 & 41 & 45 & 42 & 49 & 45 \\
\hline & Sof. point & 64 & 62 & 65 & 62 & 65 & 64 & 66 & 61 & 61 & 58 \\
\hline \multirow{2}{*}{ H/L III 3} & Penetration & 53 & 47 & 51 & 45 & 48 & 42 & 46 & 45 & 52 & 48 \\
\hline & Sof. point & 61 & 61 & 63 & 63 & 65 & 65 & 65 & 60 & 62 & 57 \\
\hline \multirow{2}{*}{ H/L IV 3} & Penetration & 59 & 49 & 56 & 46 & 53 & 43 & 50 & 45 & 57 & 49 \\
\hline & Sof. point & 63 & 59 & 64 & 61 & 66 & 61 & 66 & 58 & 60 & 54 \\
\hline
\end{tabular}

Where: $\mathrm{H}$ is asphalt $80 / 100$, and $\mathrm{L}$ is asphalt $60 / 70$.

(I, II, III, and IV) are the four different prepared epoxy resins.

$(1,2$, and 3$)$ are the used hardeners. 
Table 8. Effect of Epoxy Content, $\%$ on The Values of Penetration and Softening Point for Formulations Consisting of $90-50 \%$ Asphalt $+10-50 \%$ [resin $+40 \%$ hardener] Cured at $150-170^{\circ} \mathrm{C}$ for 15 hrs.

\begin{tabular}{|c|c|c|c|c|c|c|c|c|c|c|c|}
\hline \multirow{3}{*}{ Formulations } & \multirow{3}{*}{ Specifications } & \multicolumn{10}{|c|}{ Epoxy content, \% } \\
\hline & & \multicolumn{2}{|c|}{10} & \multicolumn{2}{|c|}{20} & \multicolumn{2}{|c|}{30} & \multicolumn{2}{|c|}{40} & \multicolumn{2}{|c|}{50} \\
\hline & & $\mathrm{H}$ & $\mathrm{L}$ & $\mathrm{H}$ & $\mathrm{L}$ & $\mathrm{H}$ & $\mathrm{L}$ & $\mathrm{H}$ & $\mathrm{L}$ & $\mathrm{H}$ & $\mathrm{L}$ \\
\hline \multirow{2}{*}{ H/L I 1} & Penetration & 45 & 35 & 44 & 31 & 39 & 31 & 42 & 34 & 46 & 37 \\
\hline & Sof. point & 54 & 61 & 55 & 64 & 57 & 62 & 60 & 59 & 56 & 56 \\
\hline \multirow{2}{*}{ H/L II 1} & Penetration & 43 & 33 & 40 & 30 & 36 & 34 & 37 & 37 & 41 & 38 \\
\hline & Sof. point & 51 & 64 & 53 & 65 & 56 & 61 & 58 & 59 & 54 & 57 \\
\hline \multirow{2}{*}{ H/L III 1} & Penetration & 39 & 30 & 36 & 28 & 31 & 32 & 31 & 35 & 37 & 35 \\
\hline & Sof. point & 51 & 65 & 54 & 66 & 56 & 66 & 59 & 62 & 55 & 58 \\
\hline \multirow{2}{*}{ H/L IV 1} & Penetration & 44 & 34 & 41 & 31 & 38 & 33 & 40 & 36 & 42 & 37 \\
\hline & Sof. point & 53 & 63 & 55 & 64 & 58 & 64 & 59 & 59 & 54 & 56 \\
\hline \multirow{2}{*}{$\mathrm{H} / \mathrm{L}$ I 2} & Penetration & 51 & 54 & 49 & 51 & 49 & 51 & 52 & 53 & 54 & 55 \\
\hline & Sof. point & 59 & 61 & 59 & 61 & 61 & 59 & 58 & 57 & 56 & 56 \\
\hline \multirow{2}{*}{ H/L II 2} & Penetration & 49 & 47 & 49 & 45 & 47 & 48 & 50 & 52 & 53 & 56 \\
\hline & Sof. point & 61 & 65 & 63 & 67 & 63 & 64 & 59 & 61 & 58 & 58 \\
\hline \multirow{2}{*}{ H/L III 2} & Penetration & 52 & 49 & 48 & 49 & 46 & 52 & 49 & 54 & 52 & 57 \\
\hline & Sof. point & 57 & 64 & 59 & 65 & 59 & 61 & 56 & 61 & 54 & 59 \\
\hline \multirow{2}{*}{ H/L IV 2} & Penetration & 54 & 52 & 51 & 50 & 51 & 50 & 53 & 53 & 56 & 55 \\
\hline & Sof. point & 64 & 66 & 65 & 67 & 67 & 65 & 63 & 63 & 60 & 60 \\
\hline \multirow{2}{*}{$\mathrm{H} / \mathrm{L} \mathrm{I} 3$} & Penetration & 57 & 44 & 53 & 41 & 51 & 43 & 54 & 46 & 59 & 49 \\
\hline & Sof. point & 59 & 63 & 62 & 63 & 62 & 60 & 58 & 57 & 54 & 55 \\
\hline \multirow{2}{*}{$\mathrm{H} / \mathrm{L}$ II 3} & Penetration & 52 & 41 & 50 & 39 & 47 & 42 & 51 & 45 & 55 & 48 \\
\hline & Sof. point & 64 & 64 & 64 & 65 & 66 & 61 & 61 & 59 & 57 & 54 \\
\hline \multirow{2}{*}{ H/L III 3} & Penetration & 53 & 42 & 50 & 42 & 49 & 44 & 49 & 47 & 54 & 50 \\
\hline & Sof. point & 61 & 65 & 63 & 66 & 64 & 62 & 62 & 59 & 59 & 53 \\
\hline \multirow{2}{*}{ H/L IV 3} & Penetration & 59 & 43 & 56 & 40 & 52 & 40 & 55 & 42 & 58 & 45 \\
\hline & Sof. point & 63 & 61 & 64 & 61 & 66 & 60 & 61 & 57 & 56 & 52 \\
\hline
\end{tabular}

Where: $\mathrm{H}$ is asphalt $80 / 100$, and $\mathrm{L}$ is asphalt $60 / 70$.

(I, II, III, and IV) are the four different prepared epoxy resins.

$(1,2$, and 3$)$ are the used hardeners. 
